\title{
AGRICULTURA DE PRECISÃO: VARIABILIDADE DOS ATRIBUTOS QUÍMICO-FÍSICOS DO SOLO E RELAÇÃO COM A PRODUTIVIDADE DO MILHO
}

\author{
Douglas Dalla Nora ${ }^{1}$, Telmo Jorge Carneiro Amado ${ }^{2}$, Paulo Alba ${ }^{3}$, Rafael Pivotto Bortolotto ${ }^{4}$, Cristiano Keller
}

\section{RESUMO}

O manejo da variabilidade do solo, com o advento da agricultura de precisão, passou a ser difundido nas áreas agrícolas, sendo que a alteração de alguns atributos químicos ou físicos do solo, principalmente em áreas sobre sistemas de irrigação, pode acarretar em perdas de produtividade e nutrientes. Nesse contexto o presente trabalho teve como objetivo avaliar espacialmente as características físico-químicas do solo sobre pivô central e suas relações com a produtividade da cultura do milho. $\mathrm{O}$ trabalho foi realizado em setembro de 2010 na cidade de Inhacorá-RS. Foram coletadas 56 amostras de solo na profundidade de $0-0,10 \mathrm{~m}$ e de $0,10-0,20 \mathrm{~m}$ em um gride amostral de 1 hectare, essas foram submetidas a análises químicas e físicas, cada ponto amostral recebeu também a avaliação da resistência à penetração e análise da produtividade do milho. Foram constatados maiores produtividades da cultura do milho nos pontos georreferenciados que apresentavam maiores índices de matéria orgânica, fósforo e potássio. As maiores produtividades da cultura do milho apresentaram relação significativa $(\mathrm{p}=0,0001)$ com a porcentagem de potássio na CTC para a camada de $0,10-0,20 \mathrm{~m}$.

Palavras-chave: Características físico-químicas, Zea mays, variabilidade espacial

\section{ABSTRACT \\ PRECISION AGRICULTURE: VARIABILITY OF PHYSICAL-CHEMICAL SOIL ATTRIBUTES AND RELATION TO CORN YIELD}

The management of soil variability from the advent of precision agriculture, has become widespread in agricultural areas. The change of some chemical or physical soil attributes, especially in areas of irrigation systems can result in lost of productivity and nutrients. This study evaluates spatially the physical-chemical characteristics of the soil in the central pivot area and relates it to a corn crop yield. The area of 56 ha belongs to a private farm of Mr. Norberto Hullman located in Inhacorá, RS, Brazil. 56 soil samples were collected in the 0-0.1 m layer, and other 56 in the 0.1-0.2 m layer, following a grid sampling of 1 ha. Soil analyses were performed for each sampling point, which also performed the evaluation of resistance to the soil penetration. Corn yield was also evaluated at the end of the cropping cycle on the same points. Highest yield values were measured at locations with highest organic matter indexes, phosphorus and potassium. The highest corn yield values presented significant $(\mathrm{p}=0.0001)$ relation with exchangeable potassium in the CTC for the 0.1-0.2 m layer.

Palavras-chave: Physical-chemical characteristics, Zea mays, spatial variability

\section{Recebido para publicação em 16/10/2012. Aprovado em 21/11/2012.}

1 - Acadêmico de Agronomia, Bolsista de Iniciação Científica PIBIC-CNPQ, UFSM. e-mail: douglasdnpg@gmail.com

2 - Engenheiro Agrônomo, Professor Titular, Bolsista CNPq Depto Solos da Universidade Federal de Santa Maria (UFSM)

3 - Engenheiro Agrônomo, Mestre, Departamento de Engenharia Rural, Universidade Federal de Santa Maria (UFSM)

4 - Engenheiro Agrônomo, Doutor, Departamento de Solos, UFSM, (rpbortolotto@yahoo.com.br)

5 - Acadêmico de Agronomia, Bolsista de Iniciação Científica PIBIC-CNPQ, Universidade Federal de Santa Maria (UFSM) 


\section{INTRODUÇÃO}

A agricultura de precisão consiste na combinação de recursos agronômicos com atributos do solo e exigências das culturas, sempre que havendo variabilidade espacial no campo (MONDO et al., 2012). Para áreas com produção altamente tecnificada, deve-se fundamentalmente conhecer a variabilidade espacial dos atributos do solo, o que pode contribuir para redução de custos e aumento de produtividade (MOLIN, 1997). Em áreas irrigadas na qual os cultivos têm maior frequência, juntamente com intensa utilização do solo associado à mecanização pesada em condições inadequadas de umidade, a variabilidade da produtividade pode expressar-se com maior significância (MICHELON et al., 2007).

A variabilidade das características dos solos é em determinado número, decorrentes da interação de fatores ligados a sua formação e de fatores que dizem respeito aos processos biológicos do local, além disso, um determinado acréscimo de variabilidade pode ser atribuído à ação antrópica nas áreas de cultivo (CARVALHO, 2003), na qual pode ser alterada pelo sistema de manejo utilizado na área (SOUZA, 1992).

De acordo com Klein et al. (1998), uma das características físicas mais afetadas pelo sistema de cultivo é a porosidade do solo e a decorrente disponibilidade de água para a planta, nesse contexto Acevedo et al. (1971) verificaram drásticas reduções no crescimento foliar do milho a partir de pequenas modificações do potencial de água no solo.

$\mathrm{O}$ acréscimo de produtividade ocasionado pela complementação hídrica provida a partir do uso de sistemas de irrigação pode em muitos casos não estar sendo alcançado quando existe compactação do solo, na qual ocasiona uma inadequada utilização da água disponível e/ou quando ocorrem limitações nutricionais das plantas (LEMAINSKI, 2007). O estudo da variabilidade da produtividade e dos parâmetros físico-químicos do solo a partir das ferramentas da agricultura de precisão tem sido pouco realizado nas áreas com irrigação com pivô central do Rio Grande do Sul. Christofidis (2007) relata que o Sul do Brasil possui 1,3 milhões de hectares irrigados o que significa $6,77 \%$ do total das áreas cultivadas, onde 35000 são com pivô central.

A existência da desuniformidade da produtividade dentro de uma área com irrigação é um fato indesejado, isso porque pode influir em resultados econômicos insatisfatórios (PAULINO et al., 2009). De acordo com Kindler (1988), em todos os modelos de eficiência econômica, o foco principal é a busca da diminuição dos custos de produção e da maximização do retorno econômico líquido por meio do tempo nos projetos de irrigação. A realização de mapas de produtividade pode ser empregada para a prospecção das causas de variabilidade, consequentemente, tais resultados podem ser eficazes na formulação de soluções para os fatores limitantes (MOLIN, 1997).

Grande parte da variabilidade registrada pelos mapas de produtividade pode ser atribuída a fatores constantes, ou que variam pouco temporalmente, enquanto outros fatores são transitórios, o que ocasiona variação de uma safra para outra (DURIGON, 2008). É de vasta importância que haja uma adequada distribuição espacial de nutrientes no solo, especialmente de nutrientes como potássio (K), na qual possui uma elevada demanda inicial, com acúmulo próximo de $40 \%$ de todo o K necessário para seu desenvolvimento, no período de desenvolvimento de 40 dias após a sua emergência (KARLEN et al., 1988).

A partir dos fatores acima descritos, este trabalho teve como objetivo avaliar espacialmente características físico-químicas do solo sobre pivô central e sua relação com a produtividade do milho.

\section{MATERIAL E MÉTODOS}

O trabalho foi realizado em setembro de 2010 na cidade de Inhacorá-RS em um Latossolo Vermelho distrófico (EMBRAPA, 2006), segundo Köppen (1931) o clima da região é classificado como subtropical úmido (Cfa) a temperatura média anual situa-se nos $17,5{ }^{\circ} \mathrm{C}$ as chuvas são 
regularmente distribuídas em todas as estações do ano atingindo uma média pluviométrica de 1600 à $1800 \mathrm{~mm}$ anuais. A área experimental compreendia 56 hectares sob pivô central (Figura 1).

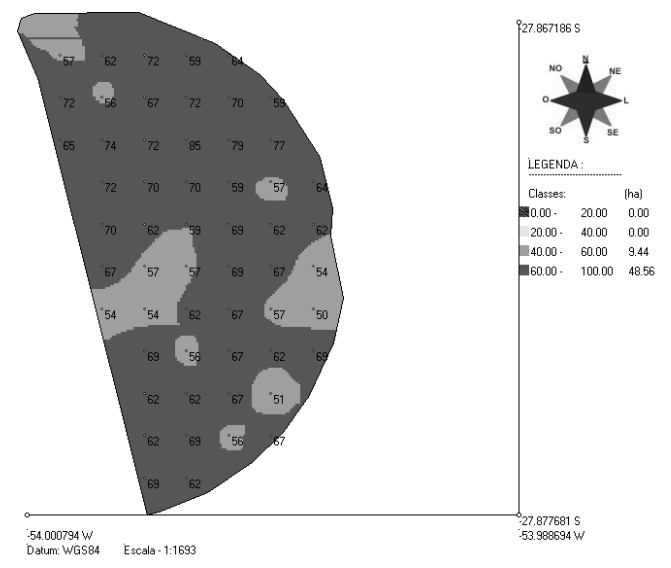

Figura 1. Modelo digital da variabilidade dos teores de argila delimitando a malha amostral da área.

A amostragem de solo foi realizada seguindo uma malha de $100 \times 100 \mathrm{~m}$ (1 ponto por ha) com 10 subamostras em torno do ponto central, a coleta das subamostras foi estratificada nas profundidades de $0,0-0,10 \mathrm{~m}$ e $0,10-0,20 \mathrm{~m}$, com o objetivo de obter resultados referentes a estratificação dos nutrientes da área experimental. As análises dos atributos químicos do solo foram realizadas no Laboratório de Manejo e Conservação do Solo da UFSM, seguindo metodologia descrita por Tedesco et al. (1995). Sendo o teor de argila das amostras determinado conforme estabelecido no método do densímetro (EMBRAPA, 1997).

Os dados georeferenciados de produtividade da cultura do milho foram obtidos com o auxílio de uma colhedora da marca Massey Ferguson, modelo MF 34, equipada com o Sistema Fieldstar e com sensor de umidade de grãos. Cada amostra foi submetida à análise química de $\mathrm{pH}$ em água determinado por potenciômetro na suspensão soloágua na proporção de 1:1, pH em índice SMP a partir do uso de uma solução tamponada a pH 7,5 proposta por Shoemaker et al. (1961), o teor de alumínio (Al) foi obtido na extração com $\mathrm{KCl} 1$ mol L-1 e titulado com $\mathrm{NaOH} 0,0125 \mathrm{~mol} \mathrm{~L}^{-1}$ (BRMA-EMBRAPA-SNLCS, 1979). As análises dos teores de $\mathrm{K}$ e Fósforo (P) do solo foram extraídos pelo método do extrator duplo ácido Mehlich-I (MEHLICH, 1953). Tais metodologias descritas são adaptadas do (TEDESCO et al., 1995).

Cada ponto amostral recebeu também a avaliação da resistência à penetração com auxílio de um penetrômetro, posteriormente foi realizada a análise de produtividade da cultura e determinação da umidade do grão (Brasil, 2009). Para a geração dos mapas de colheita, de atributos do solo e altimetria foram utilizados os softwares CR-Campeiro 7 (GIOTTO et al., 2004) e o ArcGIS 9.3 (ESRI, 2008). Para a coleta de amostras georeferenciadas e levantamento de campo utilizou-se um Pocket-PC HP® IPAQ com receptor bluetooth emparelhado com um antena de GPS Garmim ${ }^{\circledR} 10$ e GPS de navegação portátil Garmim ${ }^{\circledR}$.

\section{RESULTADOS E DISCUSSÃO}

Foi constatado que $70 \%$ da área experimental apresentava teores de argila acima de $60 \%$, sendo assim classificado como muito argiloso ou classe 4 (Figura 1), classificação essa de acordo com a Comissão de Química e Fertilidade do Solo (CQFSRS/SC), (2004). A importância do reconhecimento da variabilidade do teor de argila do solo se dá no âmbito de que este fator está diretamente correlacionado com vários processos químicos e físicos do solo como a retenção de nutrientes, a disponibilidade de água, o risco de compactação e a adsorção de agroquímicos, este último diz respeito ao ajuste da dose de agroquímicos a ser aplicada no solo, essa espacialização da percentagem de argila também está relacionada ao ajuste da pressão do disco de corte a ser utilizada durante a semeadura, o que resulta em uma maior uniformidade da profundidade de deposição das sementes (ALBA et al., 2011).

Por meio da análise da Figura 2a, foi constatado que existia uma grande variabilidade dos valores de $\mathrm{pH}$ do solo na extensão da área correspondente a 19,88 ha, esse indicador estava abaixo 5,5, valor mínimo estipulado na CQFS-RS/SC (2004). Nas regiões com índice de $\mathrm{pH}$ baixo foi verificado a presença de Al trocável nas camadas superficiais de solo, de 0,0-0,10 m (Figura 2b), tais condições revelaram que a presente situação desses pontos 
podem estar limitando a absorção de nutrientes pela planta e dessa maneira contribuindo para a diminuição da produtividade das plantas mesmo que as condições hídricas estejam ideais.

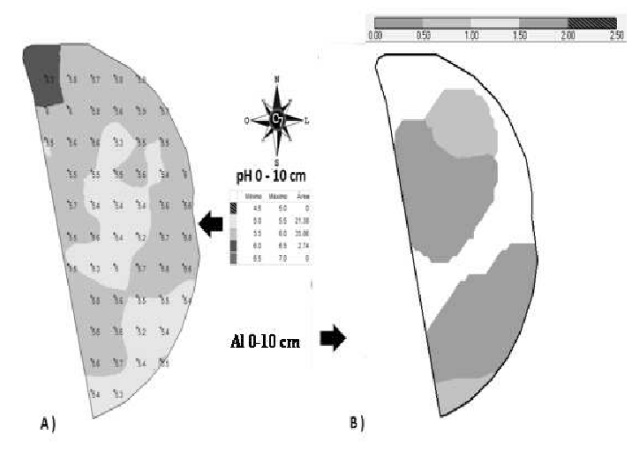

Figura 2. (a) Modelo digital da variabilidade do $\mathrm{pH}$ do solo e (b) modelo digital dos teores de alumínio.

Foi verificado que os teores de matéria orgânica do solo (MOS) estavam acima dos valores críticos estabelecidos na CQFS-RS/SC (2004), contudo foi verificada uma elevada heterogeneidade dos teores de MOS ao decorrer da área experimental, com variação na ordem de 2,90\% até 5,00 \% (Figura 3a). Vale salientar que a MOS pode ser utilizada como um dos atributos de maior relevância para a determinação da qualidade química de um solo (BEZDICEK et al., 1996; BAYER et al., 2011), uma vez que essa variável é sensível ao manejo atuando, principalmente, na retenção de água, estruturação do solo, o que reduza erosão, assim como atua como fonte primária de nutrientes (SÁ et al., 2010).

Na Figura 3b foi constatado que ocorreu uma brusca diminuição dos teores de MOS na camada de 0,10-0,20 m quando comparada a camada superficial do solo (Figura 3a). Segundo Sá e Lal (2009), a alta relação de estratificação de carbono (C) do solo, que consiste na razão entre camada superficial com elevada influência das práticas de manejo antrópicas com outra camada com baixo impacto dessas práticas, refletem ao solo uma alta qualidade superficial, inferindo em uma melhor infiltração da água e uma maior estabilidade de agregados (FERREIRA et al., 2012). Como o teor de MOS é uma relação direta com os teores de $\mathrm{C}$ do solo, foi calculada a razão entre a camada superficial de $0,01 \mathrm{~m}$ pela camada de $0,20 \mathrm{~m}$, atingindo a relação de estratificação de 1,69 , essa alta concentração de MOS na superfície do solo se deve a elevada deposição de resíduos culturais advindos das plantas de cobertura e do não revolvimento do solo. Esse enriquecimento de MOS na superfície do solo mantém a qualidade do mesmo por meio da melhor agregação, o que facilita as trocas gasosas (DORAN \& PARKING, 1994; FRANZLUEBBERS, 2007).

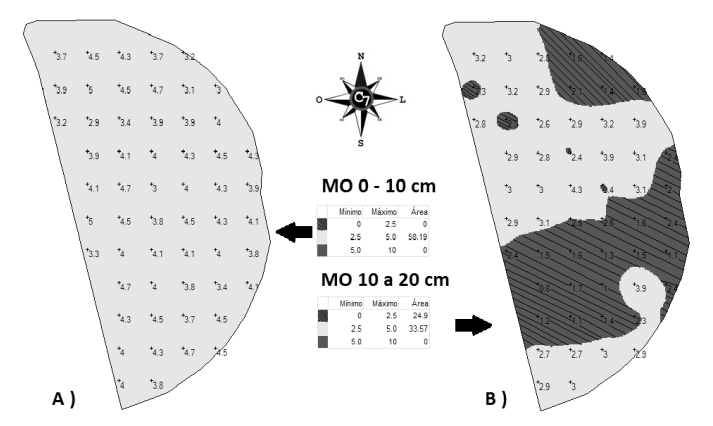

Figura 3. Modelo digital da variabilidade da porcentagem de Matéria Orgânica na camada de 0,0-0,10 m (a) e na camada de $0,10-0,20 \mathrm{~m}(\mathrm{~b})$.

A variabilidade espacial dos teores de MOS descritos na Figura 3, influenciaram nos teores de $\mathrm{K}$ de $\mathrm{P}$, como a área era submetida a aplicações de adubação a taxa fixa, os pontos que apresentaram os maiores teores de P (Figura 4a e 4b) localizaram-se concomitantemente aos pontos na qual apresentaram os maiores teores de MOS (Figura 3). Esse efeito é decorrente da liberação do $\mathrm{P}$ adsorvido no solo a partir do incremento de MOS, o que favorece a ação de fungos e bactérias específicas responsáveis pela disponibilização do $\mathrm{P}$ para as plantas.

Em sistemas de produção na qual são visados altas produtividades, a exportação de nutrientes é igualmente elevada (SOUZA et al., 2010), dessa maneira, os teores críticos para $\mathrm{P}$ e $\mathrm{K}$ propostos na CQFS-RS/SC (2004) podem não estar totalmente adequados, tornando-se, assim, fatores limitantes para esse sistema de produção (PAVINATO et al., 2008). Dessa maneira, a avaliação dos teores de $\mathrm{P} e$ $\mathrm{K}$ foram revisadas baseando-se nos teores críticos de P e K propostos por Schlindwein (2003), para Sistema Plantio Direto (SPD), teores críticos esses 
estabelecidos como $120 \mathrm{mg} \mathrm{dm}^{-3}$ de $\mathrm{K}$ e $12 \mathrm{mg}$ $\mathrm{dm}^{-3}$ de P.

A partir dos teores críticos (SCHLINDWEIN, 2003), foi verificado que existia pontos da área experimental com valores de $\mathrm{P}$ abaixo dos teores críticos (Figura 4a), esses limitavam a elevação da produtividade da área, por meio da desuniformidade da mesma. De acordo com a Figura $4 \mathrm{~b}$, foi verificado que a maioria dos pontos amostrais apresentavam-se com teores de $\mathrm{P}$ acima dos valores críticos (SCHLINDWEIN, 2003), esse efeito foi corroborado por Tucker et al. (1995) que descreve que o $\mathrm{P}$ pode deslocar-se mais rapidamente para a região de interface raiz/solo após vários anos de implementação do SPD. Mesmo que o P tenha baixa mobilidade no solo, o mesmo possui grande mobilidade no interior das plantas após ter sido absorvido pelas raízes (SANTOS et al., 2008), dessa maneira em SPD a planta pode atuar como um agente redistribuídor de $\mathrm{P}$ no perfil do solo, isso é decorrente do não revolvimento do solo, mantendo assim as raízes no seu local de origem que ao se decomporem liberam formas orgânicas e inorgânicas de $\mathrm{P}$ em regiões mais profundas do solo (SÁ, 2004).

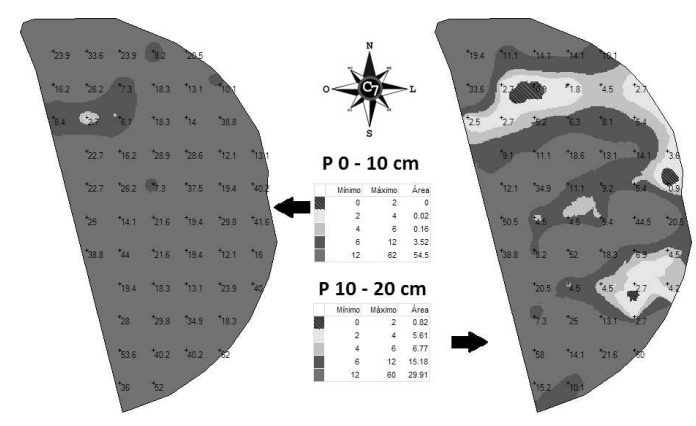

Figura 4. Modelo digital da variabilidade da porcentagem de fósforo $\left(\mathrm{mg} \mathrm{dm}^{-3}\right)$ na camada de 0,0-0,10 m (a) e na camada de $0,10-0,20 \mathrm{~m}$ (b).

$\mathrm{O}$ intenso uso de máquinas agrícolas pesadas tem modificado significativamente as propriedades físicas do solo, o tráfego intenso tem revelado camadas compactadas subsuperficialmente afetando a densidade e degradando a macroestrutura (MORAES \& BENEZ, 1996), tais características são acentuadas em SPD (BEULTER \& CENTURION, 2004). Esse efeito pode ser visualizado na Figura 5, devido a elevada resistência à penetração (RP) da área e sua desuniformidade ao decorrer da lavoura. Essa RP verificada é amplificada em áreas irrigadas, devido ao manejo sob teores de água inadequados, no solo os pontos na qual esse indicador físico estava mais elevado, ou seja, maior que 2,2 $\mathrm{MPa}$, caracterizam uma limitação para o adequado desenvolvimento radicular. Santos e Carlesso (1998) ressalvam que qualquer restrição física em alguma camada do perfil do solo que possam vir a alterar o apropriado crescimento do sistema radicular afetará a disponibilidade de água a planta.

Resistência a Penetração do Solo (MPa)

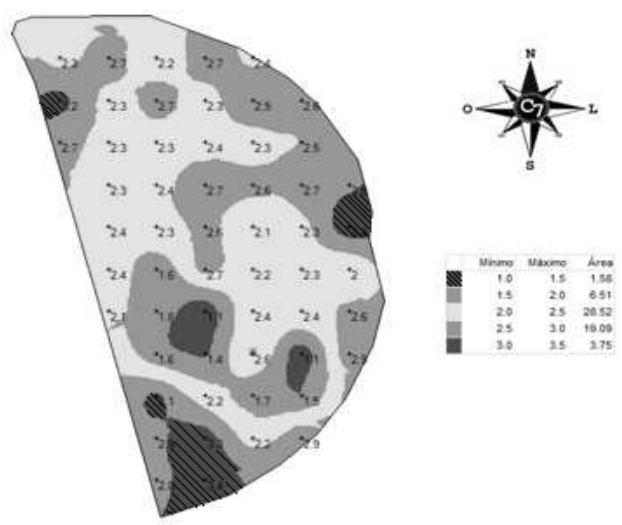

Figura 5. Modelo digital da variabilidade da resistência à penetração da área experimental.

De acordo com o que está apresentado na Figura 6 , a faixa de produtividade que apresentou a maior percentagem foi a de 9500 a $10500 \mathrm{~kg} \mathrm{ha}^{-1} \mathrm{com}$ um total de 17,92 ha, por sua vez, foram constatados os valores de 6,75 ha, na faixa de produtividade de 4400 a $8500 \mathrm{~kg} \mathrm{ha}^{-1}$, e 6,71 ha, na faixa de 11500 a $16400 \mathrm{~kg} \mathrm{ha}^{-1}$. A partir desse resultado, apesar da alta produtividade média, foi constatado que a área experimental apresentava uma elevada desuniformidade de produtividade, sendo essa no valor de $12000 \mathrm{~kg} \mathrm{ha}^{-1}$ entre o menor e a maior produtividade. Esses fatores ressaltaram a possível existência de regiões heterogêneas dentro da totalidade da lavoura, na qual exigência nutricional da cultura pode não estar sendo atendida e outras regiões ocorrendo excesso de adubação, o que ocasiona o risco de lixiviação e, consequente perda de recursos (TSCHIEDEL \& FERREIRA, 2002).

Os pontos com menores índices de $\mathrm{pH}$ (FIGURA 2a) estão situados concomitantemente aos pontos 
com menores produtividades da área experimental (Figura 6), uma vez que entre as faixas de $\mathrm{pH}$ de 5,5-6 é que ocorre maior disponibilidade de nutrientes, assim como os menores teores de Al trocável (PAVINATO \& ROSOLEM, 2008) reportando que área experimental apresentava 19,88 ha com valores de $\mathrm{pH}$ abaixo de 5,5.

De acordo com o apresentado na FIGURA 7a, a maioria dos pontos analisados apresentaram valores de $\mathrm{K}$ superiores aos níveis críticos (SCHLINDWEIN, 2003) para a camada de 0,0$0,10 \mathrm{~m}$. Por outro lado, os teores desse elemento apresentaram maior decréscimo na camada de 0,10-0,20 m (Figura 7b), provavelmente, essa elevada estratificação dos teores de K em SPD, seja um efeito resultante da elevada capacidade de ciclagem de culturas, como o milho e a aveia preta associados a adubações superficiais. Em estudo realizado por Amado et al. (2009), foi contatado uma grande estratificação do P e K sob SPD. Esse incremento de MOS na camada superficial do solo está diretamente associada ao aumento da retenção de nutrientes em superfície.

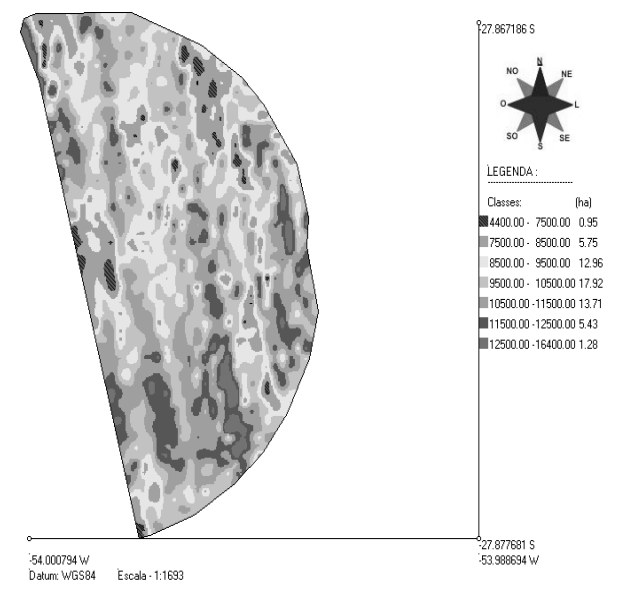

Figura 6. Modelo digital da variabilidade de produtividade da área experimental.

A variabilidade espacial dos teores de $\mathrm{K}$ na camada mais profunda $(0,10-0,20 \mathrm{~m})$ foi muito elevada (Figura 7b), os pontos amostrais que apresentaram baixos teores de $\mathrm{K}$ nessa mesma camada coincidem com os pontos amostrais que apresentaram baixas percentagens de MOS na camada de 0,10-0,20 m (Figura 3b). Esse efeito deve-se ao fato de que a disponibilidade e dinâmica do K são afetadas pelo teor de C orgânico do solo
(BAYER \& MIELNICZUK, 1997).

Dentre os atributos químico-físicos correlacionados com a produtividade do milho, a saturação de $\mathrm{K}$ na capacidade de troca de cátions (CTC) apresentou relação $(\mathrm{p}=0,001)$ com as maiores produtividades do milho, sendo que o maior produtividade do milho foi alcançada quando a saturação de $\mathrm{K}$ na CTC foi de $1,84 \%$ (Figura 8). A CTC do sistema radicular do milho é inferior quando comparada a espécies leguminosas como é o caso da soja (FERNANDES \& SOUZA, 2006), dessa maneira raízes com elevada densidade de cargas tendem a acumular íons bivalentes no entorno do perímetro radicular, em contrapartida, raízes com baixa densidade de carga apresentam maior capacidade de acumular íons univalentes (WALLACE \& SMITH 1955 apud BROYER \& STOUT, 1959), por conta desse efeito, a presença de uma maior concentração de $\mathrm{K}$ na referente camada do solo proporcionou aumento na produtividade da cultura do milho.

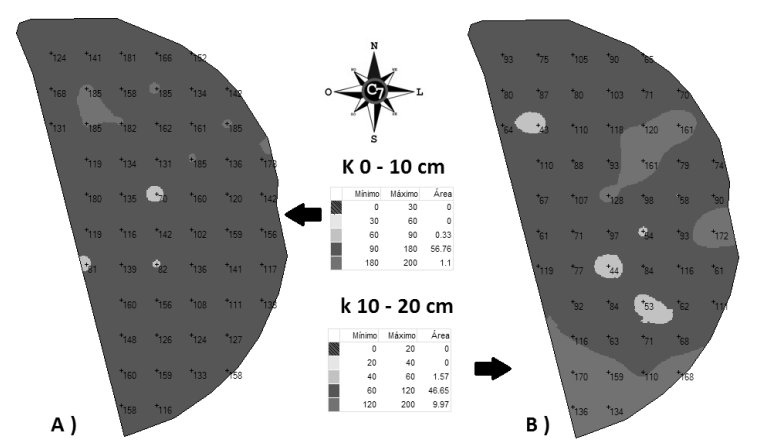

Figura 7. Modelo digital da variabilidade da porcentagem de potássio $\left(\mathrm{mg} \mathrm{dm}^{-3}\right)$ na camada de 0,0-0,10 m (a) e na camada de $0,10-0,20 \mathrm{~m}$ (b).

Mesmo sendo comumente observada a variação espacial dos teores de $\mathrm{K}$, frequentemente verificase maior acúmulo desse nutriente na região próxima ao colmo da planta ocasionando decréscimo de seus teores, à medida que ocorre um afastamento da linha de semeadura e da superfície do solo (COSTA et al., 2009). De acordo com Klepker e Anghinoni (1995), esse efeito foi nomeado de "Lavagem de K", tal fenômeno é decorrente da temporária absorção do seu teor no solo e posterior lavagem do $\mathrm{K}$ das folhas e colmos pela água da

\section{REVENG $59-68 \mathrm{p}$.}


chuva, o que gera um gradiente radial a partir do colmo (SILVA \& RITCHEY, 1982). Em trabalho realizado por Costa et al. (2009), foi verificado um acúmulo de 3,0 a 5,0 g planta-1, sendo esse valor duas vezes e meia superior a quantidade aplicada mais a concentração presente no solo.

A disponibilidade inicial dos teores de $\mathrm{K}$ são determinantes para a sua absorção e acúmulo nos tecidos da planta de milho (VYN \& JOVANICEK, 2001), ocorrendo a máxima absorção de $K$ pelo milho nas fases iniciais de desenvolvimento (COELHO, 2005), na qual ressalta a importância de existir altas concentrações desse nutriente na área compreendida pelo sistema radicular da planta. Foloni e Rosolem (2008) ressalvam na possibilidade de antecipação da adubação potássica com o intuito de suprir essa elevada demanda da cultura do milho para este nutriente. Tais resultados concretizam a necessidade de haver maior participação de $\mathrm{K}$ nos sítios de troca em maiores profundidades do solo permitindo que a cultura do milho atinja maior produtividade.

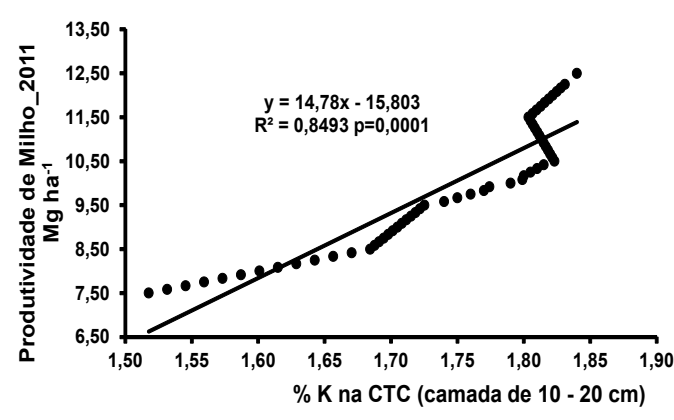

Figura 8. Correlação entre a saturação de $\mathrm{K}$ na CTC na camada de 0,10-0,20 m e a produtividade do milho.

\section{CONCLUSÕES}

- A utilização de mapas digitais possibilitou a identificação de uma elevada variabilidade dos atributos físico-químicos do solo e da produtividade da cultura do milho;

- As produtividades mais elevadas da cultura do milho apresentaram relação $(p=0,0001)$ com a concentração de K na CTC na camada de 0,10 $0,20 \mathrm{~m}$, sendo este um fator limitante para o aumento da produtividade do milho.

\section{REFERÊNCIAS BIBLIOGRÁFICAS}

ACEVEDO, E.; HSIAO, T.C.; HENDERSON, D.W. Immediate and subsequent growth response of maize leaves to changes in water status. Plant Physiology, Califórnia, v.48, p.631-636, 1971.

ALBA, P.J.; AMADO, T.J.C.; GIOTTO, E.; SCHOSSLER, D.; FIORIN, J.E. Agricultura de precisão: mapas de rendimento e de atributos de solo analisados em três dimensões. Enciclopédia Biosfera, Goiânia, v.7, p.29-41, 2011.

AMADO, T.J.C.; PES, L.Z.; LEMAINSKI, C.L.; SCHENATO, R.B. Atributos químicos e físicos de latossolos e sua relação com os rendimentos de milho e feijão irrigados. Revista Brasileira de Ciência do Solo, Viçosa, v.33, p.831-843, 2009.

BAYER, C;; AMADO, T.J.C.; TORNQUIST C.G.; CERRI.; C.E.P.; DIECKOW, J.; ZANATTA, J.A.; NICOLOSO, R.S.; CARVALHO P.C.H. Estabilização do carbono no solo e mitigação das emissões de gases de efeito estufa na agricultura conservacionista. Tópicos em Ciência do Solo, n.7, p.55-118, 2011

BAYER, C. \& MIELNICZUK, J. Características químicas do solo afetadas por métodos de preparo e sistemas de cultura. Revista Brasileira de Ciência do Solo, v.21, p.105-112, 1997.

BEULTER, A.N. \& CENTURION, J.F. Compactação do solo no desenvolvimento radicular e na produtividade da soja. Pesquisa Agropecuária Brasileira, Brasília, v.39, n.6, p.581-588, 2004

BEZDICEK, D.F.; PAPENDICK, R.I.; LAL, R. Introduction: importance of soil quality to health and sustainable land management. In: DORAN, J.W.; JONES, A.J. (ed). Methods for assessing soil quality. Madison: Soil Science Society of America, p.1-8, 1996 (SSSA. Special Publication, 49).

BRASIL. Regras para análise de sementes: Ministério da Agricultura, Pecuária e Abastecimento. Brasilia, 2009, 308p. 
BROYER, T.C. \& STOUT, P.R. The macronutrient elements. Annual Review of Plant Physiology, v.10, p.277-300, 1959

BR-MA-EMBRAPA-SNLCS. Manual de métodos de análise de solo. Rio de Janeiro, 1979, $247 \mathrm{p}$.

CARVALHO, M.T. Variabilidade espacial de atributos de um solo sob videira em Vitória Brasil (SP). Revista Brasileira de Ciência do Solo, Viçosa, v.27, n.4, p.695-703, 2003.

CHRISTOFIDIS, D. Água: um desafio para a sustentabilidade do setor agropecuário. In: IFNP. (Org.). Agrianual 2007. São Paulo: IFNP, 2007, p. 63.

COELHO, A.M. O potássio na cultura do milho. In: YAMADA, T. \& ROBERTS, T.L. Potássio na agricultura brasileira. Piracicaba, Potafos, 2005. p.613-658.

COMISSÃO DE QUÍMICA E FERTILIDADE DO SOLO RS/SC - CQFS-RS/SC. Manual de adubação e de calagem para o Estado do Rio Grande do Sul e Santa Catarina. SBCS/Núcleo Regional Sul, UFRGS, Porto Alegre, 2004, 400p.

COSTA, S.E.V.G.A.; SOUZA, E.D.;ANGHINONI, I.; FLORES, J.P.C.; ANDRIGUETTI, M.H. Distribuição de potássio e de raízes no solo e crescimento de milho em sistemas de manejo do solo e da adubação em longo prazo. Revista Brasileira de Ciência do Solo, Viçosa, v.33, p.1291-1301, 2009.

DORAN, J.W.; PARKIN, T.B. Defining and assessing soil quality. In: DORAN, J.W.; COLEMAN, D.C.; BEZDICEK, D.F.; STEWART, B.A. (Eds.). Defining soil quality for a

sustainable environment. Madison, SSSA, 1994, p.3-21.

DURIGON, R.; SCHLOSSER, J.F.; RUSSINI, A.; DORNELLES, M.E.C.; PINHEIRO, E.D. Amostragem em malha. Cultivar Máquinas, v.77, p. 12-14, 2008.
EMPRESA BRASILEIRA DE PESQUISA AGROPECUÁRIA-EMBRAPA. Centro Nacional de Pesquisa de Solos. Sistema brasileiro de classificação de solos. Embrapa Produção da Informação, Brasília, 2006, n.2, p.306.

EMPRESA BRASILEIRA DE PESQUISA AGROPECUÁRIA-EMBRAPA. Manual de métodos de analise de solo. 2.ed. Rio de Janeiro: Serviço Nacional de Levantamento e Conservação de Solos. Rio de Janeiro, 1979. 35p.

ESRI Inc. 2008. ArcMap 9.3. Redlands, Califórnia, USA.

FERNANDES, M.S. \& SOUZA, S.R. Absorção de nutrientes. In: Nutrição mineral de plantas. (ed. M.S. Fernandes). Sociedade Brasileira de Ciência do Solo, Viçosa, p.115-153, 2006.

FERREIRA, A.O.; SÁ, J.C.M.; HARMS, M.G.; BRIEDIS, C.; NETTO, C.Q.; SANTOS, L.B.S.; DIAS, C.T.S. Relação de estratificação como indicador do sequestro de carbono em macroagregados de Latossolo sob plantio direto. Ciência Rural, Santa Maria, v.42, p.645-652, 2012.

FOLONI, J.S.S. \& ROSOLEM, C.A. Produtividade e acúmulo de potássio na soja em função da antecipação da adubação potássica no sistema plantio direto. Revista Brasileira de Ciência do Solo, Viçosa, v.32, p.1549-1561, 2008.

FRANZLUEBBERS, A.J., SCHOEMBERG, H.H., ENDALE, D.M. Surface-soil responses to paraplowing of long-term no-tillage cropland in the Southern Piedmont USA. Soil and Tillage Research, Amsterdam, v.96, n.3, p.303-315, 2007.

GIOTTO, L.; ROBAINA, A.D., SULZBACH, L. A agricultura de precisão como o Sistema CR Campeiro5. Santa Maria, Universidade Federal de Santa Maria, 330p, 2004.

KARLEN, D.L.; FLANNERY, R.L. \& SADLER, E.J. Aerial accumulation and partitioning of nutrients by corn. Agronomy Journal, Madison, v.80, n.2, p.232-242, 1988. 
KLEPKER, D. \& ANGHINONI, I. Características físicas e químicas do solo afetadas por métodos de preparo e modos de adubação. Revista Brasileira de Ciência do Solo, Viçosa, v.19, p.395-401, 1995.

KINDLER, J. Modeling derived demand for irrigation water. Agriculture Water Management, Amsterdam v.13, p.403-410, 1988.

KLEIN, V.A.; LIBARD, P.L.; SILVA, A.P. Resistência mecânica do solo a penetração sob diferentes condições de densidade e teor de água. Engenharia Agrícola, Jaboticabal, v.18, n.2, p.4554, 1998.

KÖPPEN, W. Grundriss der klimakende. Leipzig: Walter de Gruyter, Berlin, 388p, 1931.

LEMAINSKI, C.L. Agricultura de Precisão em Áreas Irrigadas com Pivô Central no Rio Grande do Sul. Santa Maria: 2007, 162 f. Dissertação (Mestrado em Ciência do Solo) - Universidade Federal de Santa Maria, Santa Maria, 2007.

MEHLICH, A. Determination of P, Ca, Mg, K, $\mathrm{Na}$ and NH4 by North Carolina Soil Testing Laboratories. University of North Carolina, Raleigh, p.4, 1953.

MICHELON, C.J.; CARLESSO, R.; PETRY, M.T.; DAVID, D.; DALLA SANTA, C. Qualidade física de solos irrigados do Estado do Rio Grande do Sul. Ciência Rural, Santa Maria, v.37, n.5, p.1308-1315, 2007

MOLIN, J.P. Agricultura de precisão. Parte I: o que é o estado da arte em sensoriamento. Engenharia Agrícola, Jaboticabal, v.17, n.2, p.97-107, 1997.

П

MONDO, V.H.V.; GOMES JUNIOR, F.G.; PINTO, T.L.; MARCHI, J.L.; MOTOMIYA, A. V.A.; MOLIN, J.P.; CICERO, S.M. Spatial variability of soil fertility and its relationship with seed physiological potential in a soybean production area. Revista Brasileira de Sementes, v.34, p.193-201, 2012.

MORAES, M.H. \& BENEZ, S.H. Efeitos de diferentes sistemas de preparo do solo em algumas propriedades físicas de uma terra roxa estruturada e na produção de milho para um ano de cultivo. Engenharia Agrícola, Jaboticabal, v.16, n.2, p.3141, 1996.

PAULINO, M.A.O.; FIGUEIREDO, F.P.; FERNANDES, R.C.; MAIA, J.T.L.S.; GUILHERME, D.O.; BARBOSA, F.S. Avaliação da uniformidade e eficiência de aplicação de água em sistemas de irrigação por aspersão convencional. Revista Brasileira de Agricultura Irrigada v.3, n.2, p.48-54, 2009.

PAVINATO, P.S.; CERETTA, C.A.; GIROTTO, E.; MOREIRA, I.C.L. Nitrogênio e potássio em milho irrigado: análise técnica e econômica da fertilização. Ciência Rural, Santa Maria, v.38, n.2, p.358-364, 2008

PAVINATO,P.S.;ROSOLEM,C.A.Disponibilidade de nutrientes no Solo - decomposição e liberação de compostos orgânicos de resíduos vegetais. Revista Brasileira de Ciência do Solo, v.32, p.911-920, 2008.

SÁ, J.C.M. \& LAL, R. Stratification ratio of soil organic matter pools as an indicator of carbon sequestration in a tillage chronosequence on a Brazilian Oxisol. Soil and Tillage Research, Amsterdam, v.103, p.46-56, 2009.

SÁ, J.C.M. Adubação fosfatada no sistema plantio direto. In: IAMADA, T., ABDALLA, S.R.S. Anais do simpósio sobre fósforo na agricultura brasileira: Fósforo na agricultura brasileira. Piracicaba - SP: Associação brasileira para pesquisa da potassa e do fosfato. 2004, p.201-222.

SÁ, J.C.M.; SEGUY, L.; SÁ, M.F.M.; FERREIRA, A.O.; BRIEDIS, C.; SANTOS, J.B.; CANALLI, L.B.S. Gestão da matéria orgânica e da fertilidade do solo visando sistemas sustentáveis de produção In: Prochnow, L.I.; Casarin, V.; Stipp, S.R. (Org.). Boas Práticas para Uso Eficiente de Fertilizantes. Piracicaba, SP: International Plant Nutrition Institute - Brasil (IPNI), v.1, p.383-420, 2010. 
SANTOS, D.R.; GATIBONI, L.C.; KAMINSKI, J. Fatores que afetam a disponibilidade do fósforo e o manejo da adubação fosfatada em solos sob sistema plantio direto. Ciência Rural, Santa Maria, v.38, n.2, p.576-586, 2008

SANTOS, R.F. \& CARLESSO, R. Déficit hídrico e os processos morfológicos e fisiológicos das plantas. Revista Brasileira de Engenharia agrícola e Ambiental, Campina Grande, v.2, n.3, p.287-294, 1998.

SCHLINDWEIN, J.A. Calibração de métodos de determinação e estimativa de doses de fósforo e potássio em solos sob sistema plantio direto. 2003. 169 f. Tese (Doutorado em Ciência do Solo) - Universidade Federal do Rio Grande do Sul, Porto Alegre, 2003.

SILVA, J.E. \& RITCHEY, K.D. Acumulação diferencial de potássio em oxissolos devido a lavagem do nutriente das plantas de milho para o solo. Revista Brasileira de Ciência do Solo, Viçosa, v.6, p.183-188, 1982.

SHOEMAKER, H.E.; McLEAN, E.O.; PRATT, P.F. Buffer methods for determining lime requirement of soils with appreciable amounts of extractable aluminium. Soil Science Society of American Proceedings, Madison, v.25, p.274-277, 1961.

SOUZA, L.S. Variabilidade espacial do solo em sistemas de manejo. Porto Alegre: 1992,
162 f. Tese (Doutorado em Ciência do Solo) Universidade Federal do Rio Grande do Sul, Porto Alegre, 1992.

Sousa, G.G.; Lacerda, C.F.; Cavalcante, L.F.; Guimarães, F.V.A.; Bezerra, M.E.; Silva, G.L. Nutrição mineral e extração de nutrientes de planta de milho irrigada com água salina. Revista Brasileira de Engenharia Agrícola e Ambiental. v.14, n.11, p.1143-1151, 2010

TEDESCO, M.J.; GIANELLO, C.; BISSANI, C.A.; BOHNEN, H.; VOLKWEISS, S.J.. Análises de solo, plantas e outros materiais. Porto Alegre, Universidade Federal do Rio Grande do Sul, 174p, 1995, (Boletim Técnico, 5).

TSCHIEDEL, M. \& FERREIRA, M.F. Introdução a agricultura de precisão: conceitos e vantagens. Ciência Rural, Santa Maria, v.32, n.1, p.159-163, 2002.

TUCKER, M.R.; MESSICK, J.K.; YARBOROUGH, B., MCBRIDE, T. Soil fertility note 16: Gearing up for Consevation Tillage. February, 1995. Disponível em: www.ncagr.com agronomi. Acesso em: 27/08/2012.

VYN, T.J. \& JANOVICEK, K.J. Potassium placement and tillage system effects on corn response following longterm no till. Agronomy Journal, Madison v.3, p.487-495, 2001. 